\title{
Studi Literatur Analisis Perbandingan Arsitektur Permainan Komputer PES 2018 vs FIFA 18
}

\author{
Harya Bima Dirgantara ${ }^{1)}$, Henri Septanto ${ }^{2)}$ \\ Informatika, Institut Teknologi dan Bisnis Kalbis \\ Jalan Pulomas Selatan Kav. 22, Jakarta 13210 \\ ${ }^{1)}$ Email: harya.dirgantara@kalbis.ac.id \\ ${ }^{2)}$ Email: henri.septanto@kalbis.ac.id
}

\begin{abstract}
This literature study discusses the comparison of computer game architecture between PES 2018 and FIFA 18. Both of these games are similar and have fanbase of their respective players. This football game is popular and famous in the world. Although both are football games, but there are differences in the architecture. Game architecture in this context is the concept of the game, using reusability, determine granularity, risk bugs, and do localization. Every aspect of the architecture has an impact and influence on the end result of computer games. In the end each computer game has its own uniqueness.
\end{abstract}

Keywords: computer game architecture, granulatiry, localization, literature study

\begin{abstract}
Abstrak: Studi literatur ini membahas perbandingan arsitektur game komputer antara PES 2018 dan FIFA 18. Kedua game ini mirip dan memiliki basis penggemar masing-masing pemain. Game sepakbola ini populer dan terkenal di dunia. Meski sama-sama permainan sepakbola, tetapi ada perbedaan dalam arsitekturnya. Arsitektur game dalam konteks ini adalah konsep permainan, menggunakan reusability, menentukan granularity, risk bug, dan melakukan pelokalan. Setiap aspek arsitektur memiliki dampak dan pengaruh pada hasil akhir permainan komputer. Pada akhirnya setiap game komputer memiliki keunikan tersendiri.
\end{abstract}

Kata kunci: arsitektur game komputer, granularity, pelokalan, studi literatur

\section{PENDAHULUAN}

Permainan komputer saat ini sudah menjadi bagian dari kehidupan sehari-hari bagi pengguna komputer. Permainan komputer adalah sebuah pengalaman interaktif yang memberikan pola atau urutan tingkatan sebuah tantangan yang lamakelamaan dipahami oleh pemainnya sehingga menjadi "master" [1] [2]. Saat ini banyak sekali permainan komputer yang ada di seluruh dunia baik pada platform komputer, mobile, ataupun konsol. Setiap permainan komputer tentunya dibangun dan dikembangkan menggunakan arsitektur dan desain yang baik. Studi literatur ini membahas perbandingan arsitektur permainan komputer antara dua permainan komputer yang cukup populer, yaitu Pro Evolution Soccer (PES) 2018 dan FIFA 18. Kedua permainan ini adalah permainan bergenre sport, yaitu permainan sepakbola. Masih ada beberapa permainan komputer sepakbola lain selain keduanya itu, seperti Winning Eleven, Football Manager, ataupun Actua Soccer, namun ketiganya ini kurang populer. Permainan PES 2018 dan FIFA 18 merupakan permainan dengan genre olahraga yang memiliki karakteristik yaitu lama permainan terbatas, sehingga pemainnya dapat mengukur waktu bermainnya [3].

Setiap permainan komputer memiliki arsitektur yang menjadi dasar fondasi pengembangannya. Setiap aspek arsitektur menentukan arah pengembangan permainan komputer. Arsitektur permainan komputer dimulai dari mengkonsepkan permainan yang akan dikembangkan, menggunakan reusability, menentukan granularity, resiko bugs, dan melakukan pelokalan. Arsitektur permainan diperlukan agar sebuah permainan dapat memberikan pengalaman dan membangkitkan perasaan (senang/ cemas/ marah/ gemas) pada saat bermain. Perasaan dan pengalaman bermain dapat dipicu oleh mekanik dan kejadian dalam permainan

\section{METODE PENELITIAN}

\section{A. Konsep Studi Literatur}

Studi literatur ini bertujuan untuk menganalisis dan membandingkan arsitektur antara dua permainan komputer bergenre olahraga, yaitu 
PES 2018 dan FIFA 18 mulai dari konsep permainan, menggunakan reusability, menentukan granularity, resiko bugs, dan melakukan pelokalan.

Setiap aspek arsitektur tersebut memberikan dampak dan pengaruh pada hasil akhir permainan komputer. Konsep studi literatur ini ditampilkan pada Gambar 1. Studi literatur ini akan membahas kelima komponen arsitektur permainan komputer pada permainan PES 2018 dan FIFA 18 untuk memberi gambaran perbandingan kedua permainan tersebut. Arsitektur permainan dibangun untuk menghasilkan sebuah permainan yang menarik.

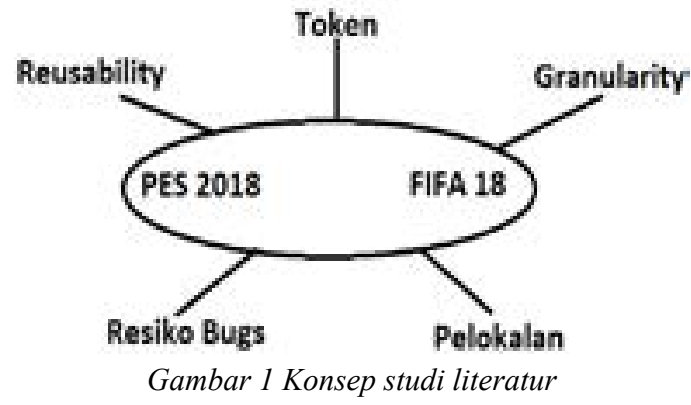

Konsep permainan dibentuk mulai pada berpikir dalam token. Token adalah seluruh elemen diskrit pada permainan komputer. Semua elemen ini diawasi dan diatur oleh komputer. Token biasanya diilustrasikan dalam bentuk hirarki seperti ditampilkan pada Gambar 1. Arsitektur tersebut dirancang agar komponen dalam permainan dapat memberikan pengalaman dan perasaan pada saat bermain. Pengalaman dan perasaan saat bermain permainan komputer dapat berasal dari [4]: pemahaman mekanik permainan, tantangan, penggunaan karakter, interaksi dengan pemain lain, ataupun teknologi yang digunakan pada permainan komputer tersebut.

\section{B. Tokenization}

Tokenization dilakukan untuk memperjelas struktur hirarki suatu permainan. Tokenization dibentuk dari token yang dapat disusun menggunakan matriks interaksi, propagasi kejadian, ataupun kelas token [3]. Pada studi literatur ini tokenization akan dibentuk dalam bentuk matriks interaksi. Contoh tokenization ditampilkan pada Gambar 2.

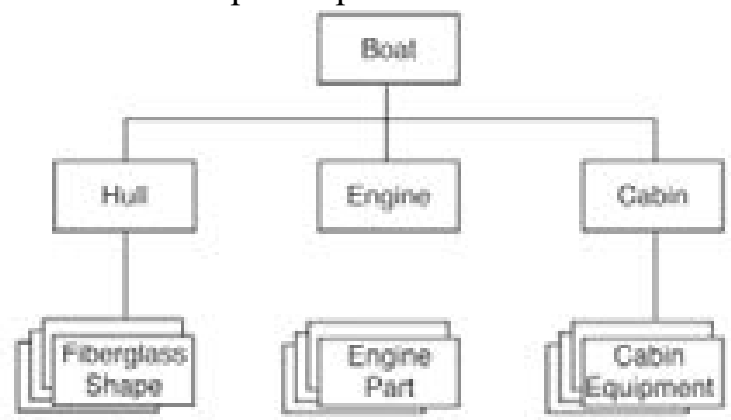

Gambar 2 Contoh tokenization [3]

\section{Granularity}

Arsitektur permainan komputer juga memerlukan penelitian tentang gameplay yang dapat memberikan pengaruh terhadap teknologi yang digunakan. Teknologi tersebut akan mempengaruhi tampilan antarmuka dan controller yang akan digunakan. Pengembangan permainan komputer selalu menggunakan reusability. Komponen yang digunakan kembali bisa merupakan code ataupun pola permainan.

Aspek granularity juga merupakan komponen arsitektur yang penting. Granularity adalah perincian jumlah elemen diskrit (token) yang terlihat pada arsitektur permainan. Contoh granularity ditampilkan pada Gambar 3.

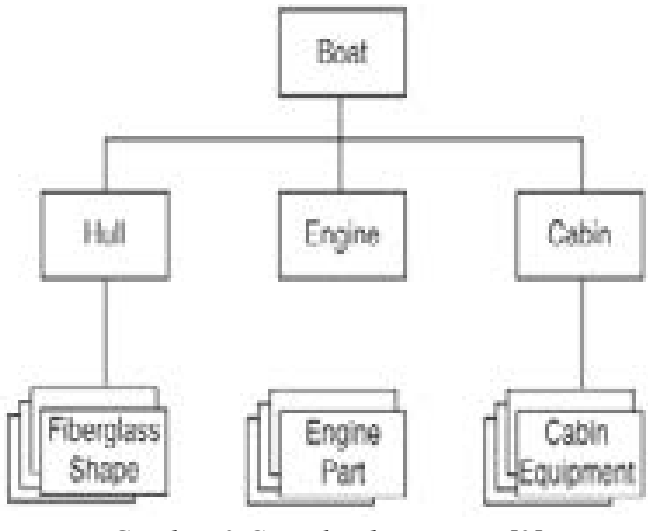

Gambar 3 Contoh tokenization [3]

\section{IIII. HASIL DAN PEMBAHASAN}

\section{A. Perbandingan Token PES 2018 dan FIFA 18}

Secara umum, token pada PES 2018 dan FIFA 18 adalah sama karena sama-sama merupakan permainan sepakbola, seperti ditampilkan pada Gambar 4 dan Gambar 5.

Token dalam permainan komputer saling berkaitan satu sama lain baik secara langsung maupun tidak langsung. Pada permainan PES 2018 dan FIFA 18 memiliki token yang sama. Permainan merupakan kompetisi yang dapat berupa liga, perebutan piala, ataupun hanya eksibisi. Ketiga jenis kompetisi ini dapat dimainkan oleh satu orang saja atau dapat dimainkan lebih dari satu orang dan maksimal empat orang. Seperti sepak bola pada umumnya, kompetisi yang dimainkan bertujuan untuk mendapatkan trofi dan penghargaan pemain secara virtual. Pada kompetisi tadi, pemain bisa menjadi tim tuan rumah dan tim tamu. Biasanya, menjadi tuan rumah memiliki sedikit keuntungan seperti kondisi pemain yang lebih bersemangat. Kedua tim (tuan rumah dan tamu) tentu saja mengejar gol untuk mendapatkan skor untuk memenangkan pertandingan. 

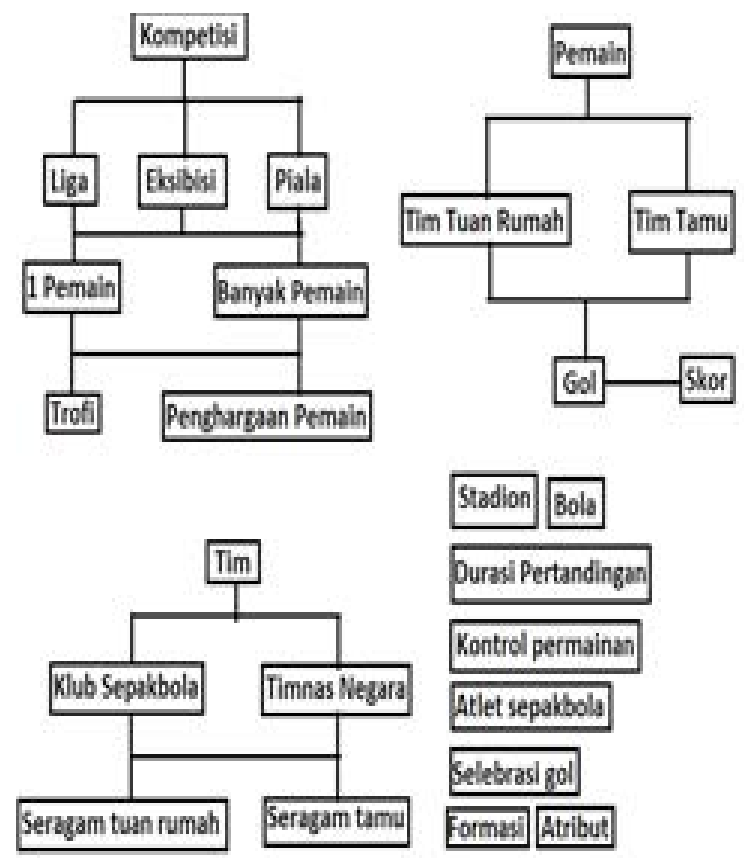

Gambar 4 Token PES 2018 \& FIFA 18 (1)
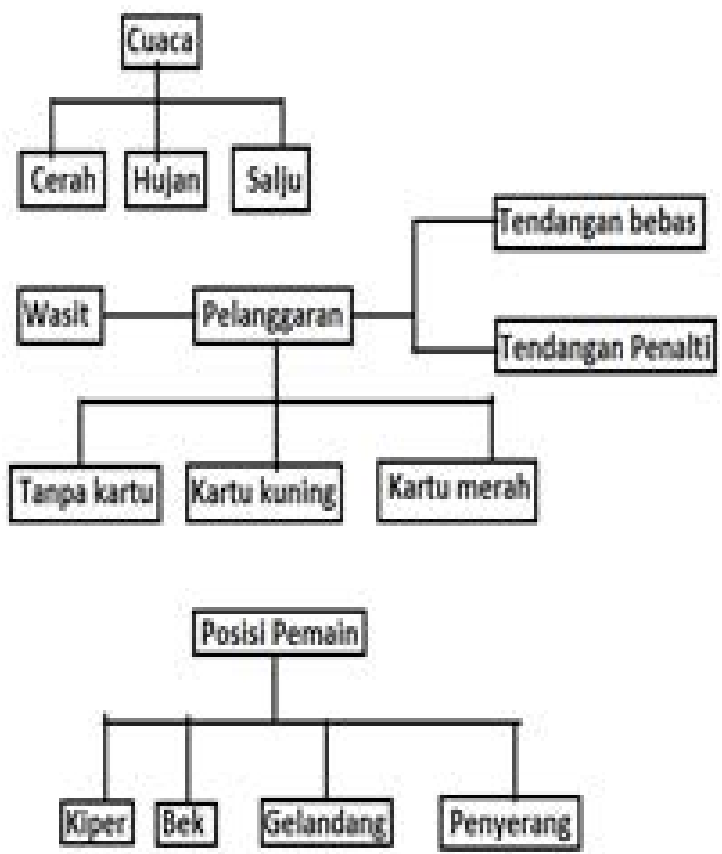

Gambar 5 Token PES 2018 \& FIFA 18 (2)

Tim yang dimainkan dapat berupa klub sepakbola ataupun tim nasional suatu negara. Pada FIFA 18 terdapat lebih dari 30 liga dan 700 tim sepakbola yang dapat dimainkan [5]. Sedangkan PES 2018 memiliki kurang lebih 7 liga dan 100 tim yang dapat dimainkan [6]. Masing-masing tim memiliki seragam sebagai tuan rumah dan seragam sebagai tamu. Cuaca pada saat pertandingan pun berbeda, terdapat cuaca saat cerah, hujan, maupun salju. Perbedaan cuaca ini memberikan pengaruh terhadap permainan, seperti pada saat cerah, permainan berjalan dengan lancar tanpa hambatan, sedangkan pada saat hujan memberikan pengaruh pada kecepatan bola, sedangkan pada cuaca bersalju akan membuat lapangan stadion menjadi licin.

Pada permainan PES 2018 dan FIFA 18 tentu saja terdapat wasit yang menjadi pengadil pertandingan. Wasit berhak menentukan suatu pelanggaran terjadi atau tidak, dari pelanggaran tersebut wasit dapat memberikan tendangan bebas atau penalti kepada tim yang dilanggara dan memberikan kartu kuning atau kartu merah kepada pelanggar. Setiap pemain sepakbola memiliki posisi masing-masing pada saat bermain. Secara umum posisi pemain adalah kiper, bek, gelandang, atau penyerang. PES 2018 dan FIFA 18 memiliki kode posisi pemain yang berbeda. Posisi pemain pada FIFA 18 lebih spesifik dibandingkan dengan PES 2018, dan terdapat perbedaan definisi pada posisi CF (Center Forward) Perbandingan kode posisi pemain ditampilkan pada Tabel 1 [7] [8].

Tabel 1 Kode posisi pemain

\begin{tabular}{rrr}
\hline Posisi & $\begin{array}{l}\text { Kode Posisi PES } \\
\mathbf{2 0 1 8}\end{array}$ & Kode Posisi FIFA 18 \\
\hline Kiper & GK (Goal Keeper) & GK (Goal Keeper) \\
\hline Bek tengah & CB (Center Back) & CB (Center Back) \\
\hline Bek tengah kiri & CB (Center Back) & LCB (Left Center Back) \\
\hline Bek tengah kanan & CB (Center Back) & RCB (Right Center \\
Bek kanan $)$
\end{tabular}

Terdapat sejumlah perbedaan pada kode posisi seorang atlet sepakbola pada PES 2018 dan FIFA 18. Namun secara umum pengertian posisinya adalah sama. Perbedaan lain adalah antara posisi penyerang, yaitu penyerang tengah pada PES 2018 disebut Center Forward, sedangkan pada FIFA 18 disebut sebagai Striker. 
Pada permainan sepakbola tentu terdapat stadion tempat bertanding, bola, atlet sepakbola serta formasi tim yang digunakan, begitu pula pada PES 2018 dan FIFA 18. Durasi pertandingan dapat diatur sesuai keinginan pemain, mulai dari 4 menit, 6 menit, 10 menit, bahkan hingga 30 menit. Jika pemain mencetak gol, maka atlet yang mencetak gol tersebut dapat berselebrasi menggunakan kontrol tertentu. Setiap atlet sepakbola memiliki atribut yang merupakan nilai atlet tersebut. Atribut antara lain adalah kemampuan menendang, mengoper, ataupun kemampuan fisik lainnya. Baik PES 2018 maupun FIFA 18 memiliki kesamaan pada atribut.

Semua token tadi merupakan elemen yang saling terkait, hubungan antara token-token tersebut ditampilkan pada tokenization berbentuk matriks interaksi pada Gambar 6. Token-token yang saling berhubungan adalah: pemain, kompetisi, tim, cuaca, wasit, posisi pemain, stadion, bola, durasi pertandingan, kontrol permainan, atlet sepakbola, selebrasi, formasi, atribut.

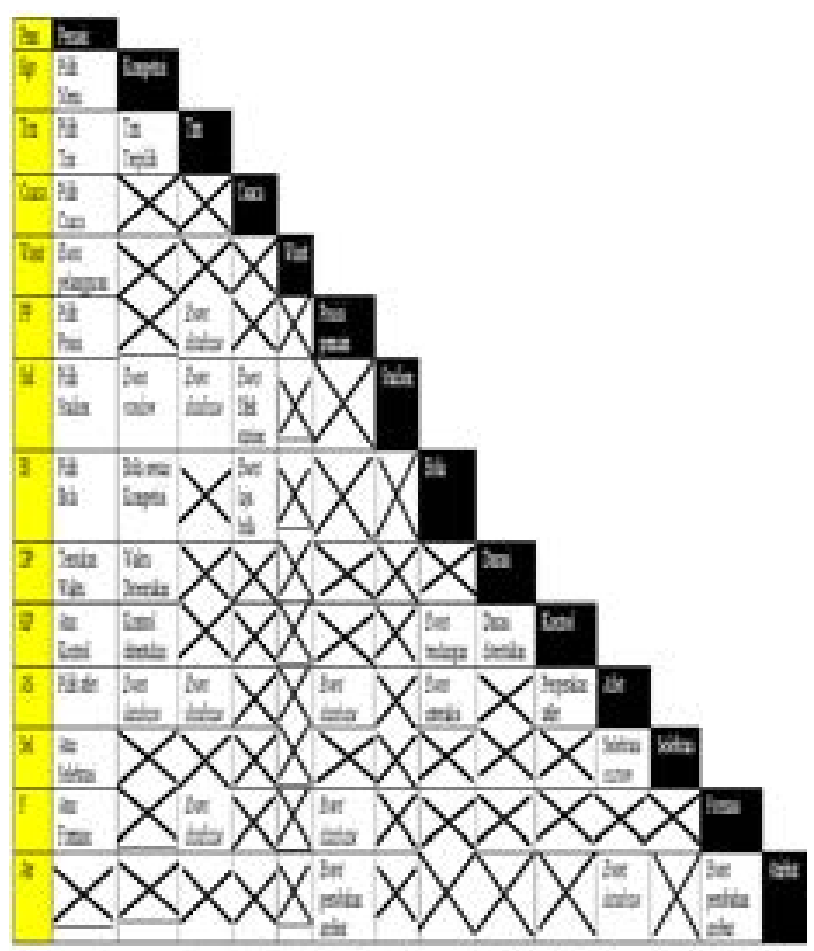

Gambar 6. Tokenization PES 2018 \& FIFA 18

Semua token saling berinteraksi, namun token wasit tidak berinteraksi langsung dengan pemain karena pemain tidak bisa mengontrol wasit. Atribut pemain akan berubah jika tida dimainkan pada posisi naturalnya. Pemain dapat mengatur kontrol permainan dengan tombol-tombol tertentu untuk bermain dan melakukan selebrasi setelah mencetak gol. Aspek arsitektur berikutnya adalah granularity, yaitu berupa perincian dari beberapa token yang ada pada permainan tersebut. Granularity permainan
PES 2018 dan FIFA 18 memiliki kesamaan seperti ditampilkan pada Gambar 7.

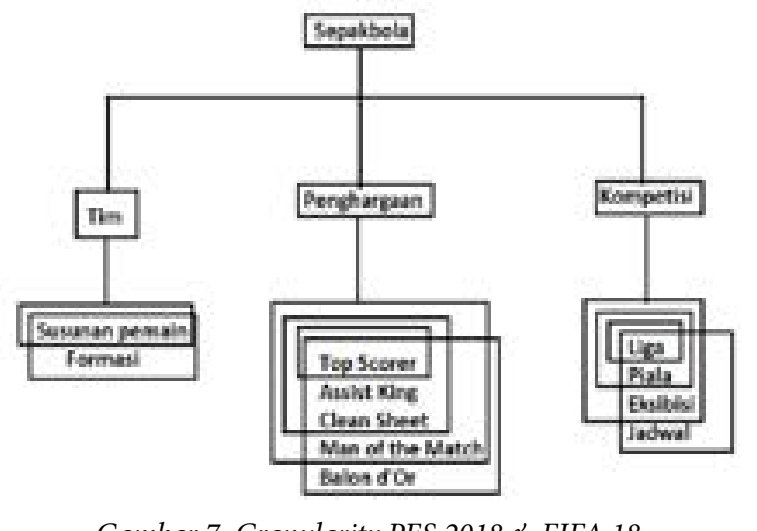

Gambar 7. Granularity PES 2018 \& FIFA 18

Permainan sepakbola jika dirinci secara umum terbagi menjadi 3 bagian besar, yaitu tim, penghargaan, dan kompetisi. Tim sepakbola pasti memiliki susunan pemain dan formasi yang khas. Tim juga pasti berkompetisi baik di liga, turnamen piala, eksibisi dan memiliki jadwal berkompetisi. Dari kompetisi tersebut akan menghasilkan penghargaan. Ketiga aspek utama inilah yang dirinci dan dikembangkan menjadi permainan komputer yang menarik.

Permainan komputer PES 2018 dan FIFA 18 bukanlah permainan baru, melainkan sudah ada sejak tahun 1990-an. Setiap tahun selalu dirilis versi barunya, sesuai musim sepakbola berlangsung. Maka itu, ada beberapa hal yang digunakan kembali. PES 2018 dan FIFA 18 memiliki konsep reusability pada pola permainan dan objek yang digunakan. Hal yang mencolok pada resuability adalah penampilan stadion dan wasit.

Aspek arsitektur lainnya adalah tentang pelokalan. Terdapat bebreapa hal yang perlu dilokalkan pada permainan PES 2018 dan FIFA 18, antara lain: lisensi dan bahasa (teks dan suara). FIFA 18 memiliki lisensi penuh atas seluruh tim (nama dan seragam) [9] yang berkompetisi di beberapa liga, sedangkan PES 2018 tidak memiliki lisensi selengkap FIFA 18, bahkan nama tim pun ada yang disamarkan karena tidak memiliki lisensi terhadap nama tim tersebut [10]. Perbandingan beberapa lisensi tim sepakbola ternama antara PES 2018 dan FIFA 18 ditampilkan pada Tabel 2.

Perbedaan antara nama tim sepakbola dikarenakan Konami selaku pemilik PES 2018 tidak memiliki lisensi dengan federasi sepakbola sedunia, yaitu FIFA. Tidak hanya nama tim, logo tim dan seragam resmi pun berbeda karena tidak memiliki lisensi. Beberapa contoh logo tim dan seragam yang berbeda pada PES 2018 dan FIFA 18 ditampilkan pada Tabel 3. Perbedaan ini terjadi karena PES 2018 
Tabel 2 Perbandingan lisensi tim sepakbola

\begin{tabular}{|c|c|c|}
\hline Nama Asli Tim & $\begin{array}{l}\text { Nama pada } \text { PES } \\
2018\end{array}$ & $\begin{array}{l}\text { Nama pada } \text { FIFA } \\
18\end{array}$ \\
\hline Chelsea & London FC & Chelsea \\
\hline Manchester City & Man Blue & Manchester City \\
\hline $\begin{array}{r}\text { Manchester } \\
\text { United } \\
\end{array}$ & Man Red & $\begin{array}{r}\text { Manchester } \\
\text { United }\end{array}$ \\
\hline $\begin{array}{r}\text { Tottenham } \\
\text { Hotspur }\end{array}$ & $\begin{array}{r}\text { North East } \\
\text { London }\end{array}$ & $\begin{array}{r}\text { Tottenham } \\
\text { Hotspur }\end{array}$ \\
\hline Real Madrid & MD White & Real Madrid \\
\hline Juventus & PM Black White & Juventus \\
\hline
\end{tabular}

tidak memiliki lisensi resmi kepada logo tim da seragam setiap tim sepakbola yang terdaftar dalam asosiasi sepakbola FIFA.

Tabel 3 Perbandingan logo tim dan searagam

\begin{tabular}{rlll}
\hline Nama Asli & $\begin{array}{l}\text { Logo dan seragam } \\
\text { Tim } \\
\text { PES } 2018\end{array}$ & $\begin{array}{l}\text { Logo dan seragam } \\
\text { FIFA 18 }\end{array}$ \\
Juventus & & & \\
\hline Manchester \\
United
\end{tabular}

Pelokalan tidak hanya terkait lisensi, namun juga mengenai pelokalan bahasa pada dalam permainan komputer, baik untuk teks dan suara. Kedua permainan komputer ini telah diakses dari seluruh dunia, sehingga membutuhkan adaptasi beberapa bahasa. Perbandingan pelokalan bahasa pada PES 2018 dan FIFA 18 ditampilkan pada Tabel 4.

Seluruh aspek arsitektur permainan komputer pada PES 2018 dan FIFA 18 menjadikan permainan tersebut dapat dimainkan dan memberikan pengalaman dan perasaan pemainnya. Mekanik dari kontrol permainan sepakbola (mengumpan, melempar, menendang, menepis, menekel, menyundul) akan memberikan suatu kejadian yang dapat memicu perasaan seseorang [1]. Contoh pada saat seorang pemain mencetak gol, maka akan terpicu perasaan senang, sedangkan bagi pemain yang gawangnya kebobolan, maka akan terpicu untuk kesal. Perasaan yang muncul ini akan lebih ekspresif apabila permainan ini dimainkan oleh 2 orang atau lebih dalam 1 perangkat. Pemain yang mencetak
Tabel 4 Pelokalan bahasa

\begin{tabular}{ll}
\hline Pilihan Bahasa PES 2018 & Pilihan Bahasa FIFA 18 \\
\hline English British & English British \\
\hline English American & English American \\
\hline Prancis & Prancis \\
\hline Belanda & Belanda \\
\hline Italia & Italia \\
\hline Spanyol & Spanyol \\
\hline Spanyol Latin & Spanyol Latin \\
\hline Rusia & Rusia \\
\hline Swedia & Swedia \\
\hline Portugis & Portugis \\
\hline Jerman & Jerman \\
\hline Portugis Brazil & Portugis Brazil \\
\hline Turki & Turki \\
\hline Korea & Korea \\
\hline Mandarin & Mandarin \\
\hline Kanton & Kanton \\
\hline Arab & Arab \\
\hline & Norwegia \\
\hline & Denmark \\
\hline & Polandia \\
\hline
\end{tabular}

gol juga dapat melakukan selebrasi unik dengan menggunakan kontrol tertentui, seorang pemain yang mengeluarkan kemampuan unik atlet sepakbola juga dapat terpicu oleh perasaan bangga dan puas karena bisa menggocek bola. Perasaan ini terpicu dari kepuasan dari memahami suatu permainan [2].

\section{SIMPULAN}

Berdasarkan hasil studi literatur ini, dapat disimpulkan bahwa FIFA 18 memiliki konten yang lebih lengkap dibandingkan dengan PES 2018 karena FIFA 18 memiliki lisensi penuh atas tim sepakbola yang terdaftar dalam asosiasi sepakbola FIFA. Dari segi penjualan permainan juga FIFA 18 jauh melebihi PES 2018. Secara garis besar, tokenization dan granularity kedua permaian ini adalah sama, karena keduanya merupakan permainan sepakbola. Kedua permainan ini memiliki fan basenya masing-masing karena kedua permainan ini memiliki ciri khasnya yang unik. Seluruh aspek arsitektur permainan komputer akan membangun suatu mekanik dan menimbulkan suatu event (kejadian) yang dapat memicu perasaan dan pengalaman bermain bagi pemainnya.

\section{DAFTAR RUJUKAN}

[1] T. Sylvester, Designing Games: A Guide to Engineering Experiences, Sebastopol: O’Reilly, 2013, hlm. 22-26.

[2] S. Swink, Game Feel: A Game Designer's Guide to Virtual Sensation, Burlington: Elsevier Inc, 2009, hlm. 99-102.

[3] A. Rollings dan D. Morris, Game Architecture and Design: A New Edition, Indianapolis: New Riders, 
2004, hlm. 73-75.

[4] G. S. Elias, R. Garfield dan K. R. Gutschera, Characteristic of Games, Massachusetts Institute of Technology Press, 2012, hlm. 122-130.

[5] EA Sports, "League and Teams," 2017. [Online]. Available: https://www.easports.com/fifa/news/2017/ fifa-18-leagues-and-teams.

[6] Trusted Reviews, "PES 2018 Teams," 2017. [Online]. Available: http://www.trustedreviews.com/news/pes2018-teams-2941096.

[7] FIFA u Teams, "Player Position," 2017. [Online]. Available: https://www.fifauteam.com/best-fifa-18players-position/.
[8] Konami, "Konami," September 2017. [Online]. Available: https://www.konami.com/wepes/2018/us/ en-us/.

[9] Footy Headlines, "FIFA 18 Licenses," 2017. [Online]. Available: https://www.footyheadlines.com/2017/09/ fifa-18-leagues-clubs-national-team-licenses-list.html.

[10] Konami, "License," 2017. [Online]. Available: https:// www.konami.com/wepes/2018/eu/en/page/license. 